\title{
Total arch replacement in the treatment of acute type A aortic dissection
}

\author{
Rizwan Q. Attia, Duke E. Cameron, Thoralf M. Sundt III, Arminder S. Jassar \\ Division of Cardiac Surgery, Corrigan Minehan Heart Center, Massachusetts General Hospital, Boston, MA, USA \\ Contributions: (I) Conception and design: RQ Attia, AS Jassar; (II) Administrative support: RQ Attia; (III) Provision of study materials or patients: \\ AS Jassar; (IV) Collection and assembly of data: RQ Attia, AS Jassar; (V) Data analysis and interpretation: All Authors; (VI) Manuscript writing: All \\ authors; (VII) Final approval of manuscript: All authors. \\ Correspondence to: Arminder S. Jassar. Division of Cardiac Surgery, Corrigan Minehan Heart Center, Massachusetts General Hospital, 55 Fruit Street, \\ Boston, MA 02114-2696, USA. Email: ajassar@mgh.harvard.edu.
}

\begin{abstract}
The role of total arch replacement (TAR) in patients with acute type A aortic dissection (ATAD) has been much debated. There are numerous factors that contribute to the clinical decision-making process. These include patient cohort, clinical status of the patient, aortic anatomy, dissection morphology, and expertise of the surgeon and the center. In this review, we summarize early and late outcomes of TAR in ATAD patients and discuss the specific patient populations that may benefit from an aggressive surgical approach at the time of the initial acute presentation. We discuss techniques for TAR, differences in aortic remodeling, and long-term aortic prognosis of these patients.
\end{abstract}

Keywords: Aortic dissection; surgery; aortic arch

Received: 04 May 2020; Accepted: 10 June 2020; Published: 20 October 2021.

doi: $10.21037 /$ jovs-20-125

View this article at: http://dx.doi.org/10.21037/jovs-20-125

\section{Introduction}

The operative standard of care for acute type A aortic dissection (ATAD) consists of ascending aortic and hemiarch replacement with an open distal anastomosis performed under hypothermic circulatory arrest (1). Proximally, the aortic valve may be resuspended or the aortic root replaced (valve sparing or Bentall), based on anatomy of the dissection. The goal of this approach is to prevent aortic rupture, preserve coronary flow, and treat aortic regurgitation, whilst excising the primary entry tear from the ascending aorta and re-establishing distal true lumen perfusion. The primary objective of the operation is to yield an alive patient, even when operated on by cardiac surgical teams without specialized aortic expertise. Downstream aortic complications can be managed by dedicated aortovascular teams later.

However, when the tear involves the aortic arch, or if the patient has distal malperfusion, this traditional paradigm may not suffice, and a more aggressive management of the aortic arch may be required. Despite the evolution of surgical techniques, cerebral protection strategies and perioperative care, surgical mortality for ATAD remains high, ranging from 10-20\% (2,3). Presence of malperfusion significantly worsens outcomes, resulting in mortality rates of approximately $40 \%$ in a recent IRAD report $(2,4)$. Several authors have recommended an aggressive early approach to the aortic arch with a total arch replacement (TAR) using either a classic elephant trunk technique (ET) $(5,6)$ or a frozen elephant trunk (FET) $(7,8)$. A more extensive early operation is justified by some to treat distal organ malperfusion and to induce positive aortic remodeling, aiming to reduce risk of late aneurysmal degeneration of the distal aorta. Presence of an ET or FET facilitates future treatment of the remaining type B component of the aortic dissection; in particular, with endovascular techniques due to creation of a robust proximal landing zone. In this review, we discuss the factors for patient selection, imaging characteristics and the operative strategies in the management of complex aortic dissection (Video 1). 


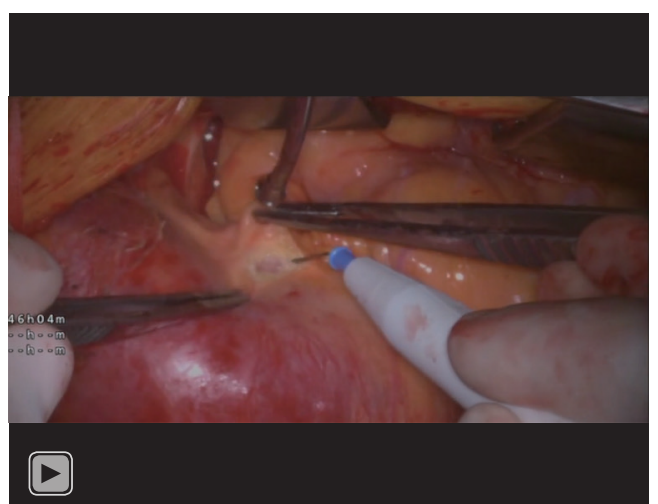

Video 1 Total aortic arch replacement for acute type A aortic dissection.

\section{Anatomical and technical considerations: dissection morphology and distal malperfusion syndromes}

Presence of an intimal tear in the aortic arch mandates a more extensive operation to completely excise the intimal tear and allow a secure distal anastomosis. Population studies of type A dissection show that $25-30 \%$ of patients have additional arch tears and or proximal descending thoracic aortic re-entry sites (5). Studies have implicated anatomical variants predisposing to dissections with entry tears in the aortic arch. In patients who underwent surgery for ATAD, 14\% either have a common origin of the innominate artery and the left common carotid artery or an origin of the left common carotid artery from the innominate artery. The rate of arch entries in this 'bovine aorta' cohort was significantly higher (59\% vs. $13 \%$, $\mathrm{P}<0.001)(9)$, making it more likely that these patients will require arch replacement. Distal aortic anastomosis can be challenging in cases where the intimal tear extends distally beyond the aortic arch and cannot be completely excised. In these situations, FET can reinforce the dissected aortic wall and at the same time allow proximalization of the distal anastomosis to a more easily accessible location in the arch. TAR with FET can also be a useful approach for patients with complicated acute type B dissection where the proximity of the dissection to the supra-aortic branches dissection precludes safe placement of a TEVAR (10).

Another subgroup of dissection patients that an extended arch operation should be considered for, are those presenting with acute end organ malperfusion (Figure 1, Video 1). End-organ malperfusion affects up to $30 \%$ of patients and increases mortality rates to $40-50 \%$
$(11,12)$. A standard hemiarch replacement will relieve distal malperfusion in approximately only $60 \%$ of the patients (13). A more aggressive operation may be warranted in these situations. Distal malperfusion is often related to large re-entry tears and true lumen collapse in the descending aorta causing impairment in abdominal visceral and renal circulations $(5,14,15)$. In these cases, true lumen reexpansion in the descending aorta may help restore blood supply to the visceral organs. Addition of a TEVAR to hemiarch replacement has been shown to improve mortality in patients presenting with acute aortic dissection and malperfusion (16). Trivedi et al. demonstrated improved outcomes with aggressive aortic arch and carotid artery replacement for patients presenting with cerebral malperfusion in the setting of ATAD $(15,16)$.

At our institution, we have adopted an approach of "verified complete reperfusion" (VCR) for all DeBakey type I dissections (10). This involves an early discussion between the cardiac and vascular surgery teams regarding the operative plan, and utilization of the hybrid operating room for all cases. After central aortic repair, distal true lumen expansion and reestablishment of visceral perfusion is confirmed using transesophageal echocardiogram (TEE), intravascular ultrasound (IVUS) and angiography. In case of ongoing compromise, additional interventions are performed immediately (generally antegrade via. the ascending aortic graft) (Figure 2, Video 1).

Strategies to treat distal aortic malperfusion include descending thoracic aortic stenting, dissection membrane fenestration or direct target vessel intervention. Use of bare metal stents across the aortic arch to treat distal dynamic malperfusion is currently being investigated and has shown promising early results with resolution of malperfusion in $90 \%$ of patients (17). Further studies are required to validate these findings, but this technology provides another option to treat distal malperfusion in ATAD patients without arch tears.

\section{Patient considerations-age and connective tissue disease}

In addition to anatomical factors, patient age and presence of connective tissue disorder must be considered when determining the extent of aortic resection. It must be noted that no specific age cut offs have been developed to distinguish young from old when treating ATAD. IRAD reports age $\geq 70$ as a significant predictor of in-hospital surgical mortality (18). Although some centres have 


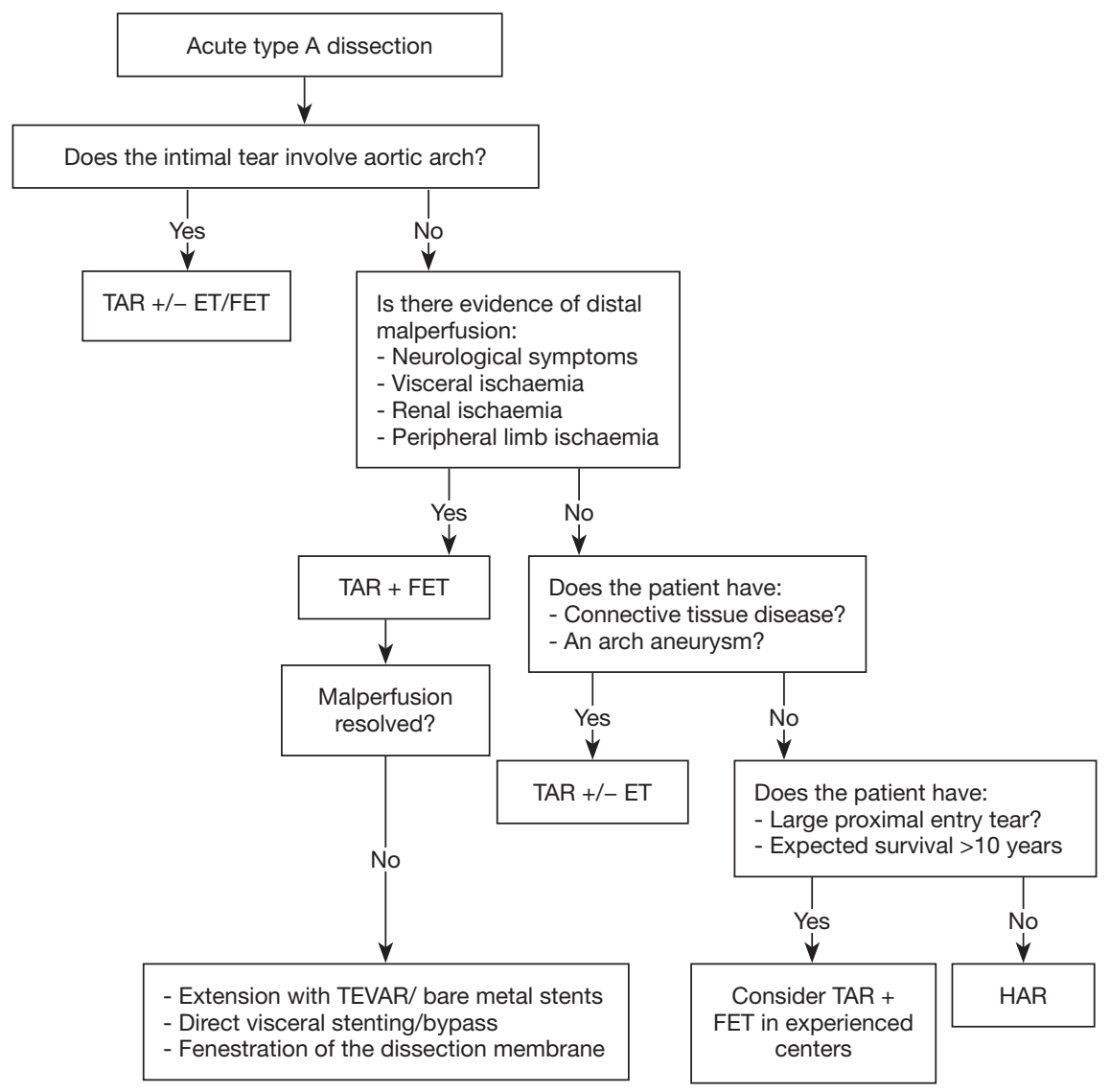

Figure 1 Outline of treatment algorithm for consideration of TAR in acute type A dissection. TAR, total arch replacement; HAR, hemi arch replacement; FET, frozen elephant trunk; TEVAR, thoracic endovascular aortic repair.

reported good short-term surgical outcomes for elderly patients with ATAD (19), exposing elderly patients to a more extensive arch operation might increase short-term risk without long-term benefit. Younger patients who are expected to live longer are at risk of further degeneration of residual dissected aorta over time and may stand to benefit more in the long-term. Data from the Yale aortic database have demonstrated average annual growth rate of $1 \mathrm{~mm}$ for ascending and $2.9 \mathrm{~mm}$ for descending aortic aneurysms (20), which may be further accelerated in the presence of aortic dissection and may result in a need for distal aortic reoperation in younger patients who are expected to survive longer (14). An individual approach that considers each patient's medical history, health condition and expected survival is warranted.

For patients with connective tissue disorders, such as Marfan and Loeys Dietz syndromes, recommendations for intervention in aneurysmal disease are clear; an earlier aggressive surgical treatment is warranted to prevent the risk of dissection and rupture $(21,22)$. The aorta is structurally abnormal throughout and that drives the need for multi segment surgery over time (23) (Figure 3). Marfan Syndrome ( $4 \%$ of ATAD) has also been shown to be a significant risk factor for recurrent aortic dissection and distal reoperation (hazard ratio 8.6) (24). In a single large series, the rate of reintervention was approximately $50 \%$ at 10 years, regardless of the index operation at dissection (23). The reoperation rate in patients with dissected arch at the time of presentation was much higher when compared to those without arch dissection. In a recent study, Chen $e t$ al. reported a $78 \%$ freedom from reoperation, and $90 \%$ freedom from death at 10 years with TAR and FET for Marfan patients in whom the dissection was limited to the thoracic aorta (25). Considering the young age at presentation and an aggressive natural history of these syndromes, early comprehensive surgical treatment might be reasonable for these patients.

High throughput genome sequencing techniques have 

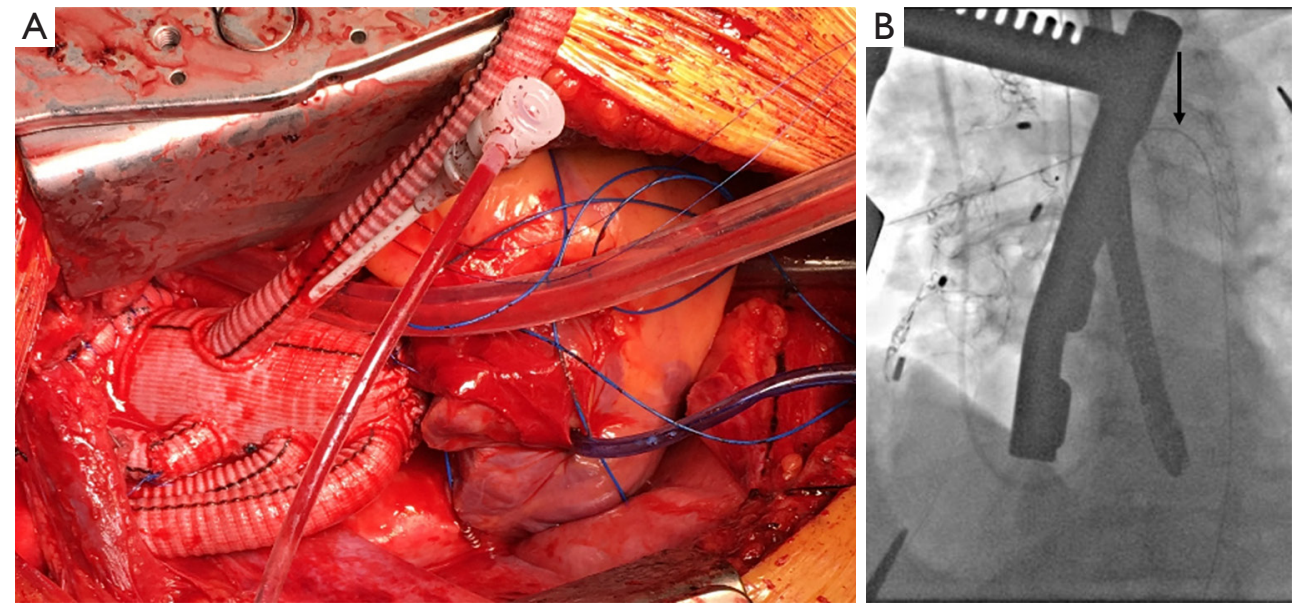

Figure 2 Confirmation of distal true lumen flow following TAR and TEVAR to proximal descending thoracic aorta. (A) Antegrade cannulation of the perfusion limb of the ascending aortic graft following a TAR for a DeBakey type I aortic dissection allows easy wire access to the true lumen of the descending thoracic aorta. (B) Fluoroscopy of the FET [the guide wire going down the proximal descending thoracic aorta (arrow)].

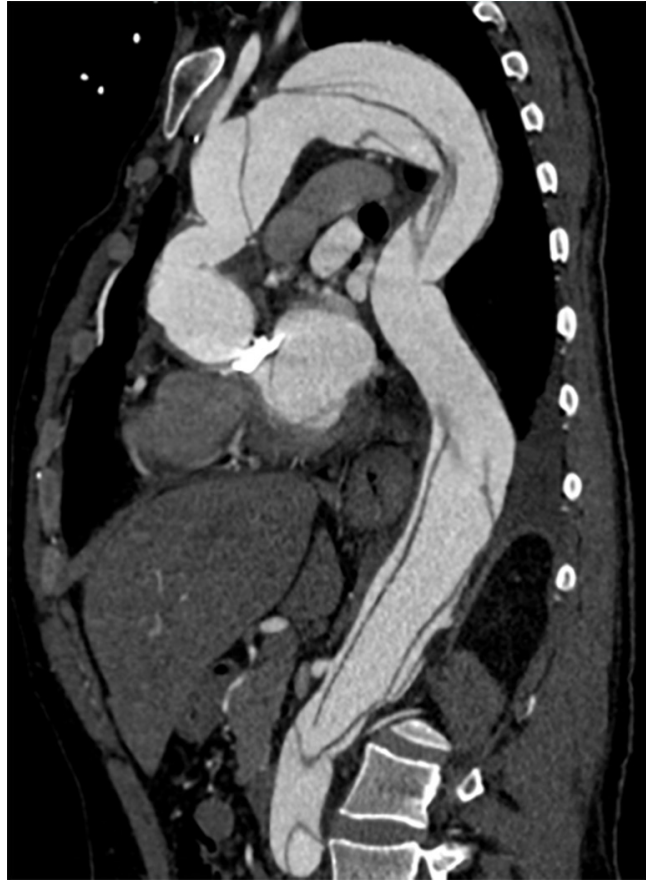

Figure 3 Residual aortic arch dissection with aneurysmal degeneration in a Marfan patient. The patient had a previous type A dissection repair with replacement of ascending aorta and mechanical Bentall.

identified non-syndromic forms of ATAD in $11-19 \%$ of the patients $(21,26,27)$. These patients may have first degree relatives with sudden cardiac death. This additional cohort of patients, when identified, would be potential candidates for early aggressive management of ATAD.

\section{Operative considerations}

Several cannulation and perfusion strategies have been described for repair of type A dissection. Operative outcomes utilizing right axillary artery, femoral artery or the ascending aorta for cannulation have been reported, with certain advantages and disadvantages described for each $(21,22,28,29)$. Femoral vessels can be rapidly cannulated, especially in emergency situations using a percutaneous approach, allowing CPB to be established prior to sternotomy. The main disadvantage is retrograde flow through dissected aorta, which can alter flow dynamics and worsen organ perfusion in some cases. Central aortic cannulation allows rapid institution of bypass and provides systemic perfusion in an antegrade fashion. However, this technique requires familiarity, and positioning of the cannula within the true lumen must be confirmed by TEE. True lumen cannulation may be challenging if the intimal tear involves the aortic arch. Right axillary artery cannulation requires extra time and an additional incision to expose the artery. The right axillary artery can either be cannulated directly (Figure 4, Video 1) or via. a side-graft. The main advantage of using the axillary artery is that it facilitates institution of antegrade cerebral perfusion during circulatory arrest. Alternative cannulation sites like the proximal innominate or right subclavian artery have also 


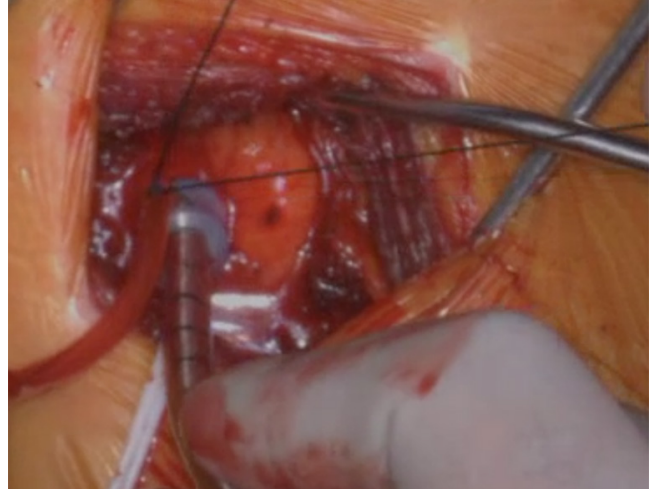

Figure 4 Direct cannulation of the axillary artery using an EOPA ${ }^{\circledR}$ cannula for instituting cardiopulmonary bypass and antegrade cerebral perfusion.

been described. In extreme situations, $L V$ apex cannulation or cannulating the ascending aorta under direct vision ("samurai technique") can be used (30). Several studies have compared the impact of cannulation site on outcomes after surgery for type A dissection repair. Kreibich et al. reported similar mortality (aortic: $10 \%$ vs. axillary: $11 \% v s$. femoral: $13 \% ; \mathrm{P}=0.680$ ) and stroke rates (aortic: $13 \%$ vs. axillary: $10 \%$ vs. femoral: $12 \% ; \mathrm{P}=0.701$ ) with central aortic, axillary or femoral cannulation (31). However, majority of the patients in this series underwent hemiarch replacement with relatively short circulatory arrest times. Interestingly, axillary artery cannulation was the predominant cannulation strategy for patients undergoing TAR. A recent large study from the STS database reported lower risk of postoperative stroke when axillary artery was used for cannulation when compared to femoral artery cannulation (OR 0.6, $\mathrm{P}<0.001)$; innominate cannulation was not different from axillary cannulation (OR 0.88; 95\% CI: 0.57-1.35; P=0.5) (32).

Debate also continues regarding the optimal cerebral protection strategy during circulatory arrest. While safety of both RCP and ACP has been demonstrated for short duration of circulatory arrest (<30-40 min), most surgeons favor antegrade cerebral perfusion for longer durations of circulatory arrest, as may be required for TAR (33). Selective myocardial perfusion during arch repair-(the "beating heart" concept) has also been described to reduce cardioplegic arrest time (34).

Studies have compared the 'island' technique (where the cephalad portion of the aortic arch that includes the arch vessels is re-implanted as a patch on the aortic graft) versus individual branch reimplantation; most have reported similar results (35). There is some concern that the island patch may degenerate over time and lead to aneurysm. The island technique may be not be technically feasible if the intimal tear extends to the greater curvature of the aortic arch. Individual branch reimplantation is generally preferred in the setting of aortic dissection, especially in patients with connective tissue disease. Individual reimplantation of the supra aortic vessels has the advantage of removing the dissected tissue in the aortic arch. Additionally, individual branch reimplantation allows early distal reperfusion after the distal anastomosis is performed as opposed to the island technique where both the distal anastomosis and the island reimplantation must be completed before visceral perfusion can be resumed. Several "off the shelf" branched grafts are available and can be used according to surgeon preference. Proximalization of the distal anastomosis to zone II rather than zone III can simplify the distal aortic anastomosis and reduce visceral ischemia time and risk of recurrent laryngeal nerve injury $(35,36)$. The base of the left subclavian artery is ligated, and the distal end of the subclavian artery is anastomosed to a branch of the aortic graft. Alternatively, an extra-anatomic bypass can be performed from the aortic graft to the axillary artery.

TAR can be combined with antegrade delivery of a stent graft into the descending aorta-the "frozen elephant trunk" technique as originally described by Borst in 1983 (36-38). Since then there have been a several new FET devices with various prefabricated grafts, such as the E-vita ${ }^{\mathrm{TM}}$ (39), Thoraflex $^{\mathrm{TM}}$ (40), Cronus (41) and Frozenix-J graft (42). These hybrid devices consist of a conventional surgical graft that is mated to a stented endovascular graft, thus eliminating the possibility of a type I endoleak. Presence of a sewing cuff facilitates the distal anastomosis. The endograft helps seal the surgical suture line and reduces the risk of bleeding from fragile aortic tissues. If a distal aortic intervention is required later, shifting the treatment level to the mid thoracic aorta with the use of either a classic or FET facilitates a technically easier re-operation that avoids hypothermic circulatory arrest and reduces risk of recurrent laryngeal nerve injury. If no pre-mated hybrid FET devices are available, the surgeons can use a commercially available TEVAR graft that is deployed into the descending aorta during circulatory arrest and can be then incorporated into the distal aortic anastomosis (43-45).

When deploying TEVAR antegrade during ATAD, care must be taken to ensure that stent graft is positioned in the true lumen distally. As direct visualization is not always possible, this can be accomplished by passing a guidewire 
into the descending aorta under IVUS or TEE guidance prior to initiating circulatory arrest. Alternatively, a sterile bronchoscope can be inserted into the distal aorta during circulatory arrest to confirm true lumen deployment of the stent graft. Oversizing the stent graft is not necessary; the FET/TEVAR component is true sized to the aortic lumen to prevent aortic rupture. Spinal cord ischemia remains a concern with use of FET. Spinal drains are usually not advisable due to the emergency nature of the operation. Risk of spinal cord ischemia can be reduced by using a short segment (usually $10 \mathrm{~cm}$ ) stent graft (46).

FET is a useful technique when the intimal tear or rupture extends to the distal arch, and the aortic tissue is fragile and dissected. A stented graft can reinforce the aortic wall and provide a robust zone for anastomosis. An alternative but more invasive technique to address an intimal tear that extends beyond the aortic arch is to perform the anastomosis in the descending aorta. This can be accomplished by extending the sternotomy transversely using a left thoracotomy, usually in the fourth intercostal space (47). The right pleura is opened to allow retraction of the heart to the right side. This provides excellent exposure of the descending aorta down to the level of the inferior pulmonary veins.

In the absence on an aortic arch tear, it is reasonable to consider replacing an aneurysmal aortic arch that would otherwise meet guideline criteria for replacement $(21,28)$.

\section{Early outcomes}

Several authors have reported good operative results with TAR in the setting of ATAD, leading some to recommend TAR for all patients with $\operatorname{ATAD}(7,48)$. This recommendation is based on early results and favorable long-term remodeling after TAR compared to hemiarch only. If a distal re-operation is required, presence of an elephant trunk facilitates open and endovascular treatment for ATAD patients. When considering hemiarch versus TAR for ATAD, the short-term risk of complications of TAR must be considered. There is no debate that TAR is a more technically complex operation compared to hemiarch replacement. Surgeon expertise must be considered in this decision-making. Although some studies have reported higher mortality with TAR than with hemiarch replacement, the IRAD and GERAADA registries showed no significant difference in mortality between the two approaches $(2,49-52)$. However, risk of neurologic, renal and respiratory complications may be higher with TAR $(32,52)$. It must also be noted that distal aortic reintervention is required in only $10-30 \%$ of patients after hemiarch repair for ATAD (53). Thus, a policy of "total arch for all" exposes a majority of patients to additional risks with potentially limited and possibly no benefit. Several studies have compared outcomes of hemiarch to TAR for ATAD. Omura et al. reported similar in-hospital mortality rates for total arch $(10.2 \%)$ and partial arch replacement $(14.7 \%, \mathrm{P}=0.47)$. In multivariate analysis, TAR was not a significant risk factors for in-hospital mortality (54). Sun et al. have reported operative mortality around $8 \%$ with a $2 \%$ stroke and a $3 \%$ paraplegia rate for TAR in ATAD (48). A meta-analysis of several single center studies reporting outcomes in TAR for ATAD show a pooled hospital mortality rate of 8.6\% (95\% CI: 7.2-10) (55) (Table 1). Rates of stroke and spinal cord ischemia were $5.7 \%$ (95\% CI: 3.6-8.2) and $2 \%$ (95\% CI: 1.2-3) (54,55). Other meta-analysis data suggest no significant differences in-hospital mortality between hemiarch and TAR $(52,56)$. While individual center studies report excellent short-term outcomes, these results are to be interpreted with caution as they may suffer from a publication bias as most reports come from centers with specialized expertise in aortic surgery. It should be kept in mind that analyses from contemporary large registries continue to show in-hospital mortality rates of $18-20 \%$ for all-comers with $\operatorname{ATAD}(14,49)$.

\section{Medium- and long-term outcomes-survival, aortic remodeling and reoperation}

Late survival after ATAD repair is reduced as compared to the general population with estimated 5, 10 and 15 year survival rates of $82 \%, 64 \%$, and $48 \%$ respectively (57). Aortic events in the descending thoracic aorta account for majority of the late deaths with up to $12-24 \%$ of patients die from late distal aortic rupture $(58,59)$. This includes aneurysm rupture or complications related to aneurysm repair during re-operation. In a large series of 728 patients, late survival and freedom from reintervention were $89 \%$ and $85 \%$ respectively at 8 years. Other series with over 2 decades of follow-up demonstrate freedom for reoperation at 10 years at $74 \%$ (60). Twenty percent of ATAD patients remain at risk for secondary intervention, based on negative remodeling in subsequent surveillance scans (61-63). A non-resected primary entry tear and Marfan syndrome are known independent predictors of late reoperation (60). The onset of enlargement is unpredictable but risk factors include initial aortic diameter at presentation, elevated 


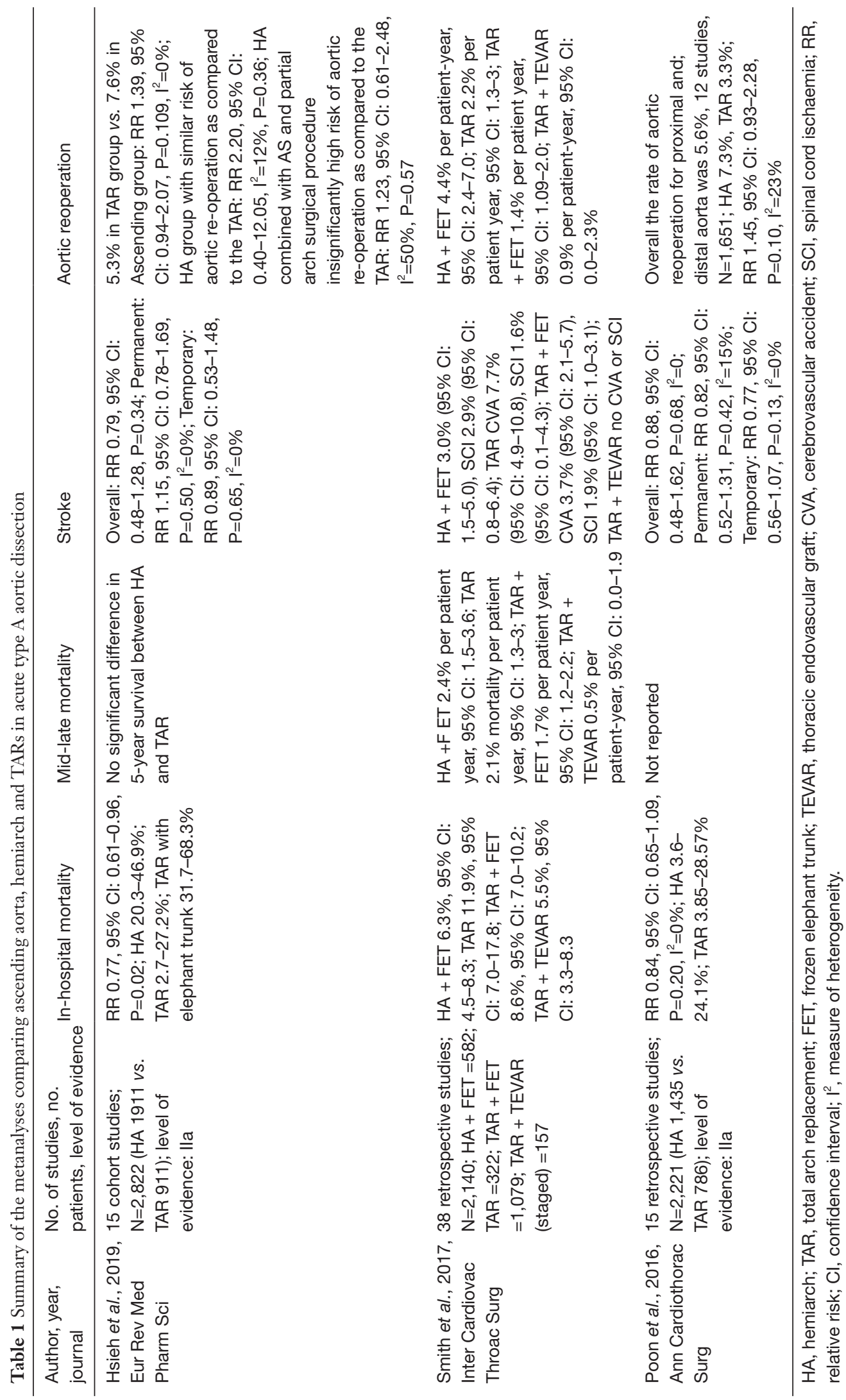


blood pressure and patent false lumen post-repair $(57,58)$. The main risk factor for reintervention on the arch or descending thoracic aorta after proximal aortic repair is the persistent flow in the false lumen, which is associated with aneurysmal degeneration of the dissected aorta $(52,55,56)$. Presence of a tear in the descending aorta on post-operative scans predicts failure of the aorta to remodel $(64,65)$ as these communications between lumina infer pressurization of the false lumen and unlikely false lumen thrombosis (66). Analysis of pre-discharge CT scans after ATAD repair demonstrate additional entry tears in the proximal descending thoracic aorta in $38 \%$ of cases, distal descending thoracic aorta in $25 \%$ and abdominal aorta in $41 \%$ of patients (67). Freedom from reintervention is significantly lower patients with an intimal tear in the proximal descending aorta. These aortas are likely to expand at a much faster rate of up to $7.6 \mathrm{~mm} /$ year proximally and $6.8 \mathrm{~mm} /$ year distally. Multivariate analysis showed that proximal re-entry tears are an independent variable for risk of aortic reintervention (HR 4.99, $\mathrm{P}=0.004)$ and significant aortic expansion (HR 4.21, $\mathrm{P}=0.002$ ) (67).

In cases where the primary entry tears are located in the aortic arch and/or proximal descending thoracic aorta, arch replacement with FET allows false lumen exclusion leading to false lumen thrombosis and its obliteration $(61,65,68)$. Available long-term data suggest that aortic remodeling with partial or complete thrombosis of the persistent false lumen can be expected in approximately $90 \%$ of cases along the length of the stent graft (69-71). Having an ET or FET facilitates tackling the remaining dilated and dissected aorta, either using endovascular or open approach.

Omura et al. reported late outcomes for patients undergoing partial arch $v s$. TAR for ATAD (54). During a mean follow-up period of $60 \pm 48$ months, 5 -year survivals in the TAR and hemiarch/partial arch replacement groups were $88.6 \% \pm 4.2 \%$ and $83.8 \% \pm 4.4 \%$, respectively $(\mathrm{P}=0.54)$. Rates of distal aortic events (defined as freedom from surgery for distal aorta dilation or distal arch diameter expanding to $50 \mathrm{~mm}$ ) at 5 years were significantly better in the TAR group than in the non-TAR group $(94.9 \% \pm 3.5 \%$ vs. $83.6 \% \pm 4.9 \%, \mathrm{P}=0.01)$. However, freedom from surgery at 5 and 10 years was $94.9 \% \pm 3.5 \%$ and $91.7 \% \pm 4.6 \%$ in the TAR group, respectively, and $90.9 \% \pm 3.6 \%$ and $83.3 \% \pm 5.3 \%$ in the hemiarch/partial arch group, with no significant difference between the groups $(\mathrm{P}=0.20)(54)$.

There have been three systematic reviews and metaanalyses published on extended repair of type A aortic dissections (Table 1) $(52,55,56)$. These report outcomes in about 2,000 patients from 38 studies. Patients underwent either TAR, TAR with FET, hemi-arch and FET or TAR with creation of a landing zone for antegrade or retrograde TEVAR. The results were compared to patients who had clamped ascending aorta replacement or open distal hemi arch replacement. The reports include a heterogenous patient population within the cohort of ATAD. There were multitude of cannulation, cardiopulmonary bypass, myocardial and cerebral protection strategies deployed. The results were further confounded by inclusion of patients from the Far East, Europe, and North America, where patients may present at various stages of the evolution of ATAD. It is especially problematic to tease out patients who presented early or late or where there was a delay in diagnosis and end-organ malperfusion or shock. For geographical reasons certain centers, tend to receive patients which are "self-selected" as survivors by presenting 24-48 hours after the index event. A meta-analysis of 2,822 patients by Hsieh et al. showed that ascending aortic replacement had a significantly lower risk of in-hospital mortality, shorter cardiopulmonary bypass time, circulatory arrest time and antegrade cerebral perfusion time (56). Incidence of neurological dysfunction and renal dialysis were not significantly different between the groups. The pooled rate of aortic re-operation was lower in total arch group (5.3\% vs. 7.6\%), albeit not significantly (RR 1.39; 95\% CI: 0.94-2.07; P=0.10). Meta-analysis by Poon et al. comparing hemiarch $v$ s. TAR for ATAD (2,221 patients from 14 retrospective studies) showed no significant difference in in-hospital mortality between the two groups, however, TAR was associated with a higher risk of postoperative renal dialysis (52). The rate of re-operation for proximal and distal aorta was $7.3 \%$ in hemiarch and $3.3 \%$ in extensive TAR, although there was no statistical significance detected between groups (RR 1.45; 95\% CI: $\left.0.93-2.28 ; \mathrm{P}=0.10, \mathrm{I}^{2}=23 \%\right)$. A pooled linearized rate of late mortality of $0.5 \%$ per patient-year (95\% CI: $0.0-1.9)$ and late reoperation of as $0.9 \%$ per patient-year (95\% CI: $0.0-$ 2.3) have been reported for TAR with staged TEVAR. (55). This is compared to hemiarch repair with FET having late mortality of $2.4 \%$ per patient-year (95\% CI: $1.5-3.6)$ and late reoperation rate of $4.4 \%$ per patient-year $(95 \% \mathrm{CI}$ : 2.4-7.0) (Table 1).

These data show that TAR with FET positively impacts distal aortic remodelling and suggest that it may potentially reduce distal reoperation rates. More studies that show a clear reduction in reoperation rate and improved survival are needed before considering TAR with FET can be 
recommended for all patients with ATAD.

\section{Conclusions}

The optimal strategy for management of the aortic arch in aortic dissection remains controversial. High volume aortic centres with non-randomised data sets demonstrate equivalent early mortality between hemi arch and TAR patients and no significant increase in stroke or paraplegia rates. They also demonstrate superior late outcomes in the total arch patients with positive aortic remodelling. Some studies suggest high early mortality with TAR, while other studies have demonstrated excellent operative outcomes $(53,72)$. There may be an inherent publication bias, with only high-volume centers with experience in TAR publishing their results, making it difficult to generalize those results to the entire cardiac surgical community. Even if these results are achieved in most centres; we must still focus on identifying those patients most likely to benefit from such an aggressive approach. This may include patients with dissection involving the arch, entry tears in the arch and/or proximal descending aorta, patients with connective tissue disease, younger patients and those with end-organ malperfusion that would not be corrected unless flow to the true lumen is restored (73). Some patients with large proximal descending thoracic aortic intimal tears or severe true lumen collapse may benefit from TAR and FET for long term aortic remodeling, but only when performed by experienced teams. Ongoing surveillance is mandatory for all patients after repair for ATAD. Risk stratification could allow a bespoke approach to aortic dissection surgery.

\section{Acknowledgments}

Funding: None.

\section{Footnote}

Provenance and Peer Review: This article was commissioned by the Guest Editors (Ibrahim Sultan and George Arnaoutakis) for the series "Advancement in the Surgical Treatment of Aortic Dissection" published in Fournal of Visualized Surgery. The article has undergone external peer review.

Conflicts of Interest: All authors have completed the ICMJE uniform disclosure form (available at https://jovs. amegroups.com/article/view/10.21037/jovs-20-125/coif).
The series "Advancement in the Surgical Treatment of Aortic Dissection" was commissioned by the editorial office without any funding or sponsorship. TMS serves as an unpaid international advisory board member of fournal of Visualized Surgery. The authors have no other conflicts of interest to declare.

Ethical Statement: The authors are accountable for all aspects of the work in ensuring that questions related to the accuracy or integrity of any part of the work are appropriately investigated and resolved. All procedures performed in this study were in accordance with the Helsinki Declaration (as revised in 2013). The manuscript is waived from patient informed consent according to the ethics committee or institutional review board.

Open Access Statement: This is an Open Access article distributed in accordance with the Creative Commons Attribution-NonCommercial-NoDerivs 4.0 International License (CC BY-NC-ND 4.0), which permits the noncommercial replication and distribution of the article with the strict proviso that no changes or edits are made and the original work is properly cited (including links to both the formal publication through the relevant DOI and the license). See: https://creativecommons.org/licenses/by-nc-nd/4.0/.

\section{References}

1. Sultan I, McGarvey J, Vallabhajosyula P, et al. Routine use of hemiarch during acute type A aortic dissection repair. Ann Cardiothorac Surg 2016;5:245-7.

2. Collins JS, Evangelista A, Nienaber CA, et al. Difference in clinical presentation, management, and outcomes of acute type a aortic dissection in patients with and without previous cardiac surgery. Circulation 2004;110:II237-42.

3. Olsson C, Thelin S, Ståhle E, et al. Thoracic aortic aneurysm and dissection: increasing prevalence and improved outcomes reported in a nationwide populationbased study of more than 14,000 cases from 1987 to 2002. Circulation 2006;114:2611-8.

4. Berretta P, Trimarchi S, Patel HJ, et al. Malperfusion syndromes in type A aortic dissection: what we have learned from IRAD. J Vis Surg 2018;4:65.

5. Di Marco L, Leone A, Murana G, et al. Acute type A aortic dissection: Rationale and outcomes of extensive repair of the arch and distal aorta. Int J Cardiol 2018;267:145-9.

6. Czerny M, Schmidli J, Adler S, et al. Current Options and Recommendations for the Treatment of Thoracic 
Aortic Pathologies Involving the Aortic Arch: An Expert Consensus Document of the European Association for Cardio-Thoracic Surgery (EACTS) \& the European Society for Vascular Surgery (ESVS) 2. Eur J Cardiothorac Surg 2019;5 5:133-62.

7. Shrestha M, Fleissner F, Ius F, et al. Total aortic arch replacement with frozen elephant trunk in acute type A aortic dissections: are we pushing the limits too far? Eur J Cardiothorac Surg 2015;47:361-6; discussion 366.

8. Shrestha M, Martens A, Kaufeld T, et al. Single-centre experience with the frozen elephant trunk technique in 251 patients over 15 years. Eur J Cardiothorac Surg 2017;52:858-66.

9. Dumfarth J, Plaikner M, Krapf C, et al. Bovine aortic arch: predictor of entry site and risk factor for neurologic injury in acute type a dissection. Ann Thorac Surg 2014;98:1339-46.

10. Axtell A, Eagleton M, Conrad M, et al. Total Arch Replacement and Frozen Elephant Trunk for Acute Complicated Type B Dissection. Ann Thor Surg 2020. doi:10.1016/j.athoracsur.2019.12.077.

11. Czerny M, Schmidli J, Bertoglio L, et al. Clinical Cases Referring to Diagnosis and Management of Patients With Thoracic Aortic Pathologies Involving the Aortic Arch: A Companion Document of the 2018 European Association for Cardio-Thoracic Surgery (EACTS) and the European Society for Vascular Surgery (ESVS) Expert Consensus Document Addressing Current Options and Recommendations for the Treatment of Thoracic Aortic Pathologies Involving the Aortic Arch. Eur J Vasc Endovasc Surg 2019;57:452-60.

12. Yang B, Patel HJ, Williams DM, et al. Management of type A dissection with malperfusion. Ann Cardiothorac Surg 2016;5:265-74.

13. Grimm JC, Magruder JT, Crawford TC, et al. Differential outcomes of type A dissection with malperfusion according to affected organ system. Ann Cardiothorac Surg 2016;5:202-8.

14. Pape LA, Awais M, Woznicki EM, et al. Presentation, Diagnosis, and Outcomes of Acute Aortic Dissection: 17Year Trends From the International Registry of Acute Aortic Dissection. J Am Coll Cardiol 2015;66:350-8.

15. Di Eusanio M, Trimarchi S, Patel HJ, et al. Clinical presentation, management, and short-term outcome of patients with type A acute dissection complicated by mesenteric malperfusion: observations from the International Registry of Acute Aortic Dissection. J Thorac Cardiovasc Surg 2013;145:385-90.e1.
16. Vallabhajosyula P, Gottret JP, Menon R, et al. Central Repair With Antegrade TEVAR for Malperfusion Syndromes in Acute Debakey I Aortic Dissection. Ann Thorac Surg 2017;103:748-55.

17. Bozso SJ, Nagendran J, Chu MWA, et al. Single-Stage Management of Dynamic Malperfusion Using a Novel Arch Remodeling Hybrid Graft. Ann Thorac Surg 2019;108:1768-75.

18. Rampoldi V, Trimarchi S, Eagle KA, et al. Simple risk models to predict surgical mortality in acute type A aortic dissection: the International Registry of Acute Aortic Dissection score. Ann Thorac Surg 2007;83:55-61.

19. Ikeno Y, Yokawa K, Yamanaka K, et al. Total arch replacement in octogenarians and nonagenarians: A singlecenter 18-year experience. J Thorac Cardiovasc Surg 2019. doi:10.1016/j.jtcvs.2019.07.092.

20. Coady MA, Rizzo JA, Hammond GL, et al. What is the appropriate size criterion for resection of thoracic aortic aneurysms? J Thorac Cardiovasc Surg 1997;113:476-91.

21. Erbel R, Aboyans V, Boileau C, et al. 2014 ESC Guidelines on the diagnosis and treatment of aortic diseases. Eur Heart J 2014;35:2873-926.

22. Hiratzka LF, Bakris GL, Beckman JA. 2010 ACCF/AHA/ AATS/ACR/ASA/SCA/SCAI/SIR/STS/SVM guidelines for the diagnosis and management of patients with thoracic aortic disease. J Am Coll Cardiol 2010;55:e27-e129.

23. Schoenhoff FS, Jungi S, Czerny M, et al. Acute Aortic Dissection Determines the Fate of Initially Untreated Aortic Segments in Marfan Syndrome. Circulation 2013;127:1569-75.

24. Ma WG, Chen Y, Zhang W, et al. Limited versus extended repair for acute type A aortic dissection: longterm outcomes of the Beijing approach beyond 10 years. J Cardiovasc Surg (Torino) 2020. doi: 10.23736/S00219509.20.11293-X.

25. Chen Y, Ma WG, Li JR, et al. Can Frozen Elephant Trunk Cure Type I Dissection Confined to Thoracic Aorta in Marfan Syndrome? Ann Thorac Surg 2020;109:1174-82.

26. De Backer J, Campens L, De Paepe A. Genes in thoracic aortic aneurysms/dissections - do they matter? Ann Cardiothorac Surg 2013;2:73-82.

27. Nishimura RA, Otto CM, Bonow RO, et al. 2014 AHA/ ACC guideline for the management of patients with valvular heart disease: executive summary: a report of the American College of Cardiology/American Heart Association Task Force on Practice Guidelines. J Am Coll Cardiol 2014;63:2438-88.

28. Hiratzka LF, Bakris GL, Beckman JA. 2010 ACCF/AHA/ 
AATS/ACR/ASA/SCA/SCAI/SIR/STS/SVM guidelines

for the diagnosis and management of patients with Thoracic Aortic Disease: a report of the American College of Cardiology Foundation/American Heart Association Task Force on Practice Guidelines, American Association for Thoracic Surgery, American College of Radiology, American Stroke Association, Society of Cardiovascular Anesthesiologists, Society for Cardiovascular Angiography and Interventions, Society of Interventional Radiology, Society of Thoracic Surgeons, and Society for Vascular Medicine. Circulation 2010;121:e266-369.

29. Kreibich M, Desai ND, Bavaria J. Preoperative neurological deficit in acute type A aortic dissection. Interact Cardiovasc Thorac Surg 2020;30:613-9.

30. Kitamura T, Torii S, Kobayashi K, et al. Samurai cannulation (direct true-lumen cannulation) for acute Stanford Type A aortic dissection. Eur J Cardiothorac Surg 2018 Sep 1;54:498-503.

31. Kreibich M, Chen Z, Rylski B, et al. Outcome after aortic, axillary, or femoral cannulation for acute type A aortic dissection. J Thorac Cardiovasc Surg 2019;158:27-9.

32. Ghoreishi M, Sundt TM, Cameron DE, et al. Factors associated with acute stroke after type A aortic dissection repair: An analysis of the Society of Thoracic Surgeons National Adult Cardiac Surgery Database. J Thorac Cardiovasc Surg 2020;159:2143-54.e3.

33. Chen E, Gleason T, Yang B, et al. Discussions in Cardiothoracic Treatment and Care: The Contemporary Management of Acute Type A Aortic Dissection. Semin Thorac Cardiovasc Surg 2020;32:202-10.

34. Martens A, Koigeldiyev N, Beckmann E, et al. Do not leave the heart arrested. Non-cardioplegic continuous myocardial perfusion during complex aortic arch repair improves cardiac outcome. Eur J Cardiothorac Surg 2016;49:141-8.

35. Lin Y, Ma WG, Zheng J, et al. Supra-aortic vessel reconstruction in total arch replacement for acute type A dissection: Comparison of en bloc and separate graft techniques. Asian J Surg 2019;42:482-7.

36. Kato M, Ohnishi K, Kaneko M, et al. New graftimplanting method for thoracic aortic aneurysm or dissection with a stented graft. Circulation 1996;94:II188-93.

37. Suto Y, Yasuda K, Shiiya N, et al. Stented elephant trunk procedure for an extensive aneurysm involving distal aortic arch and descending aorta. J Thorac Cardiovasc Surg 1996;112:1389-90.

38. Fleck T, Hutschala D, Czerny M, et al. Combined surgical and endovascular treatment of acute aortic dissection type A: preliminary results. Ann Thorac Surg 2002 Sep;74:7615; discussion 765-6.

39. Jakob H, Tsagakis K, Leyh R, et al. Development of an integrated stent graft-dacron prosthesis for intended one-stage repair in complex thoracic aortic disease. Herz 2005;30:766-8.

40. Shrestha M, Pichlmaier M, Martens A. Total aortic arch replacement with a novel four-branched frozen elephant trunk graft: first-in-man results. Eur J Cardiothorac Surg 2013;43:406-10.

41. Ma WG, Zheng J, Sun LZ, et al. Open Stented Grafts for Frozen Elephant Trunk Technique: Technical Aspects and Current Outcomes. Aorta (Stamford) 2015;3:122-35.

42. Okita Y. Current surgical results of acute type A aortic dissection in Japan. Ann Cardiothorac Surg 2016;5:368-76.

43. Jassar A, Kreibich M, Morlock J, et al. Aortic Replacement After TEVAR-Diameter Correction With Modified Use of the Siena Prosthesis. Ann Thorac Surg 2018;105:587-91.

44. Eldeiry M, Aftab M, Bergeron E, et al. The Buffalo Trunk Technique for Aortic Arch Reconstruction. Ann Thorac Surg 2019;108:680-6.

45. Preventza O, Coselli JS, Mayor J, et al. The Stent Is Not to Blame: Lessons Learned With a Simplified US Version of the Frozen Elephant Trunk. Ann Thorac Surg 2017;104:1456-63.

46. Preventza O, Liao JL, Olive JK, et al. Neurologic complications after the frozen elephant trunk procedure: A meta-analysis of more than 3000 patients. J Thorac Cardiovasc Surg 2020;160:20-33.e4.

47. Kim JB, Sundt TM. Best surgical option for arch extension of type B aortic dissection: the open approach. Ann Cardiothorac Surg 2014;3:406-12.

48. Ma WG, Zhang W, Wang LF, et al. Type A aortic dissection with arch entry tear: Surgical experience in 104 patients over a 12-year period. J Thorac Cardiovasc Surg 2016;151:1581-92.

49. Easo J, Weigang E, Hölzl PPF, et al. Influence of operative strategy for the aortic arch in DeBakey type I aortic dissection: analysis of the German Registry for Acute Aortic Dissection Type A. J Thorac Cardiovasc Surg 2012;144:617-23.

50. Conzelmann LO, Weigang E, Mehlhorn U, et al. Mortality in patients with acute aortic dissection type A: analysis of pre- and intraoperative risk factors from the German Registry for Acute Aortic Dissection Type A (GERAADA). Eur J Cardiothorac Surg 2016;49:e44-52. 
51. Larsen M, Trimarchi S, Patel HJ, et al. Extended versus limited arch replacement in acute Type A aortic dissection. Eur J Cardiothorac Surg 2017;52:1104-10.

52. Poon SS, Theologou T, Harrington D, et al. Hemiarch versus total aortic arch replacement in acute type A dissection: a systematic review and meta-analysis. Ann Cardiothorac Surg 2016;5:156-73.

53. Rylski B, Beyersdorf F, Kari FA, et al. Acute type A aortic dissection extending beyond ascending aorta: Limited or extensive distal repair. J Thorac Cardiovasc Surg 2014;148:949-54; discussion 954.

54. Omura A, Miyahara S, Yamanaka K, et al. Early and late outcomes of repaired acute DeBakey type I aortic dissection after graft replacement. J Thorac Cardiovasc Surg 2016;151:341-8.

55. Smith HN, Boodhwani M, Ouzounian M, et al. Classification and outcomes of extended arch repair for acute Type A aortic dissection: a systematic review and meta-analysis. Interact Cardiovasc Thorac Surg 2017;24:450-9.

56. Hsieh WC, Kan CD, Yu HC, et al. Ascending aorta replacement vs. total aortic arch replacement in the treatment of acute type A dissection: a meta-analysis. Eur Rev Med Pharmacol Sci 2019;23:9590-611.

57. Olsson C, Hillebrant CG, Liska J, et al. Mortality and reoperations in survivors operated on for acute type $\mathrm{A}$ aortic dissection and implications for catheter-based or hybrid interventions. J Vasc Surg 2013;58:333-9.e1.

58. Fattouch K, Sampognaro R, Navarra E, et al. Long-Term Results After Repair of Type A Acute Aortic Dissection According to False Lumen Patency. Ann Thorac Surg 2009;88:1244-50.

59. Halstead JC, Meier M, Etz C, et al. The fate of the distal aorta after repair of acute type A aortic dissection. J Thorac Cardiovasc Surg 2007;133:127-35.

60. Zierer A, Voeller RK, Hill KE, et al. Aortic enlargement and late reoperation after repair of acute type A aortic dissection. Ann Thorac Surg 2007;84:479-86; discussion 486-7.

61. Gorlitzer M, Weiss G, Meinhart J, et al. Fate of the false lumen after combined surgical and endovascular repair treating Stanford type A aortic dissections. The Ann Thorac Surg 2010;89:794-9.

62. Trimarchi S, Tolenaar JL, Jonker FH, et al. Importance of false lumen thrombosis in type B aortic dissection prognosis. J Thorac Cardiovasc Surg 2013;145:S208-12.

63. Fattori R, Bacchi-Reggiani L, Bertaccini P, et al. Evolution of aortic dissection after surgical repair. Am J Cardiol
2000;86:868-72.

64. Pan XD, Bin Li, Ma WG, et al. Endovascular repair of residual intimal tear or distal new entry after frozen elephant trunk for type A aortic dissection. J Thorac Dis 2017;9:529-36.

65. Iida Y, Fujii S, Shimizu H, et al. Patterns of aortic remodelling after total arch replacement with frozen elephant trunk for acute aortic dissection. Interact Cardiovasc Thorac Surg 2019;29:923-9.

66. Dohle DS, Tsagakis K, Janosi RA, et al. Aortic remodelling in aortic dissection after frozen elephant trunk. Eur J Cardiothorac Surg 2016;49:111-7.

67. Kim JH, Lee SH, Lee S, et al. The Impact of a Reentry Tear After Open Repair of Nonsyndromic Acute Type I Aortic Dissection. Ann Thorac Surg 2019. doi: 10.1016/ j.athoracsur.2019.10.062.

68. Tsagakis K, Tossios P, Kamler M, et al. The DeBakey classification exactly reflects late outcome and reintervention probability in acute aortic dissection with a slightly modified type II definition. Eur J Cardiothorac Surg 2011;40:1078-84.

69. Tsagakis K, Pacini D, Di Bartolomeo R. Arch replacement and downstream stent grafting in complex aortic dissection: first results of an international registry. Eur J Cardiothorac Surg 2011;39:87-93; discussion 93-4.

70. Uchida N, Shibamura H, Katayama A, et al. Total arch replacement with an open stent graft for acute type A aortic dissection: fate of the false lumen. Eur J Cardiothorac Surg 2009;35:83-8.

71. Di Marco L, Pantaleo A, Leone A, et al. The Frozen Elephant Trunk Technique: European Association for Cardio-Thoracic Surgery Position and Bologna Experience. Korean J Thorac Cardiovasc Surg 2017;50:1-7.

72. Kim JB, Chung CH, Moon DH, et al. Total arch repair versus hemiarch repair in the management of acute DeBakey type I aortic dissection. Eur J Cardiothorac Surg 2011;40:881-7.

73. Shrestha M, Bachet J, Bavaria J, et al. Current status and recommendations for use of the frozen elephant trunk technique: a position paper by the Vascular Domain of EACTS. Eur J Cardiothorac Surg 2015;47:759-69.

doi: 10.21037/jovs-20-125

Cite this article as: Attia RQ, Cameron DE, Sundt TM 3rd, Jassar AS. Total arch replacement in the treatment of acute type A aortic dissection. J Vis Surg 2021;7:46. 